\title{
Correction to: Schmidentity and informativity
}

\section{Hannes Fraissler ${ }^{1}$}

Published online: 5 August 2020

() Springer Nature B.V. 2020

\section{Correction to: Synthese https://doi.org/10.1007/s11229-020-02698-w}

The original article has been corrected. The author also wants to add the following addendum to the article.

Shortly after the present article was published online, I was informed of Salmon (2018). The fact that I missed this important contribution requires some corrections of what I said here: It is not true that Kit Fine's theory of semantic relationism is "not clearly subject to the schmidentity argument," as I suggested in the first paragraph of Sect. 7. Salmon (2018, pp. 217 ff) neatly executes a schmidentity argument against Fine's semantic relationism, which I just vaguely imagined in n. 39 (Sect. 6). Since I take Salmon's argument to be convincing, there cannot be any doubt that Fine's semantic relationism is susceptible to the schmidentity argument, and the ratio I mentioned in n. 13 (Sect. 3) significantly shifts in favor of successful applications of schmidentity-like arguments in Salmon's work. I wish to thank Nathan Salmon for favorably providing me with his recent article, which I find myself in broadest agreement with.

Publisher's Note Springer Nature remains neutral with regard to jurisdictional claims in published maps and institutional affiliations.

The original article can be found online at https://doi.org/10.1007/s11229-020-02698-w.

$\triangle$ Hannes Fraissler

hannes.fraissler@gmail.com

1 Institute of Philosophy, Université du Luxembourg, Maison des Sciences Humaines, 11, Porte des Sciences, Esch-sur-Alzette 4366, Luxembourg 